\title{
A Theory on Origin of Speculative Bubbles and Public Debt Accumulation
}

\author{
Masayuki Otaki \\ Institute of Social Sciences, University of Tokyo, Tokyo, Japan \\ Email: ohtaki@iss.u-tokyo.ac.jp
}

How to cite this paper: Otaki, M. (2016) A Theory on Origin of Speculative Bubbles and Public Debt Accumulation. Theoretical Economics Letters, 6, 1169-1179. http://dx.doi.org/10.4236/tel.2016.65110

Received: September 27, 2016

Accepted: October 17, 2016

Published: October 20, 2016

Copyright $\odot 2016$ by author and Scientific Research Publishing Inc. This work is licensed under the Creative Commons Attribution International License (CC BY 4.0).

http://creativecommons.org/licenses/by/4.0/

(c) (i) Open Access

\begin{abstract}
I define a speculative bubble as the phenomenon in which zero expected return assets possess positive economic values. The limited liability principle matters in such a case. Individual investors prefer higher risk and higher return assets under limited liability, and they become incautious about the downside risk. Accordingly, even the zero expected return assets have a positive market value. However, we must note that some substantial amount of government subsidies should be introduced into the market to penetrate the limited liability principle. As circulating such assets implies the prevalence of economy-wide zero-sum game, if we presume the limited liability principle, additional provision of an official subsidy is unavoidable to finance the private positive gains. This finding implies that the precariousness of whether a speculative bubble emerges vitally depends on the fiscal discipline of a government. Whenever investors foresee a government's forbearing policy, they invest in riskier zero-sum assets, and there emerges a more violent speculative bubble. In such a case, a huge amount of public debt is accumulated as a result of the government's aids. I negate not only the Ricardian equivalence theorem under non-altruistic individuals but also the Lerner's assertion that alleges the issuance of a public debt to be irrelevant to the future resource allocation. Therefore, speculative bubbles genetically distort the intergenerational resource allocation, and hence, intergenerational ethic on the macroeconomic policy should be urgently established.
\end{abstract}

\section{Keywords}

Speculative Bubbles, Limited Liability, Moral Hazard, Public Debt, Intergenerational Ethic

\section{Introduction}

There is a serious drawback in the popular speculative bubble theory, which originates 
from Blanchard and Watson [1]. In such a model, the rate of return from a bubbly asset is equal to the rate of interest. As historical evidences show, the rate of return for a bubbly asset is far beyond such a level. This paper provides the reason why the bubbly asset explodes so rapidly.

I define a speculative bubble as a phenomenon where a valueless asset possesses a positive market value. The limited liability with imperfect information plays a crucial role. Using the partial equilibrium framework developed by Stiglitz and Weiss [2], one can show that when an asset has a non-zero probability of strictly positive return, the price of such an asset becomes positive owing to the limited liability principle even though the expected return is zero. As the monetary authority is assumed to be less informative than investors, the authority cannot assess the riskiness of the investor's asset sufficiently. Mathematically, this is an application of Jensen's inequality.

It is also worthy to note that when one evaluates the riskiness of assets by the secondorder stochastic dominance (i.e., mean preserving spread), lenders prefer riskier assets. Intuitively, the probability density function of a second-order stochastic dominated asset is "fat tailed" when compared with the original asset, and thus, the probability of extremely high and low returns becomes significant. The limited liability principle cuts off the downside risk. Consequently, a higher risk and higher return asset fascinates investors even though the expected return of the asset is zero and valueless for risk averse agents. This paper regards this process as the origin and explosion of speculative bubbles.

The point to be emphasized here is that huge costs are involved in penetrating the limited liability principle. Whenever the expected return is zero, the transaction of such an asset can be regarded as a zero-sum game played within an overall economy. Accordingly, many investors are defeated in this bet and pay their losses that amount to their capital loss. However, defeated investors get rid of excess payment beyond their wealth due to the limited liability principle; thus, a government is eventually encountered by the total amount of capital loss of the overall economy. In Japan, the government expenditure, which aims at the depreciation of non-performing debts and reviving the construction and real estate industry, soared up to about 50 trillion yen after the bust of the bubble in the 1990s. A huge amount of money is generated by the new and provocative issuance of public debt. Thus, speculative bubbles are always terminated by annihilating fiscal discipline.

One must note that individuals who live during the bubble era (even after the bust of bubble) enjoy a higher utility compared with generations before and after such a calamity. This is partly because the average high private return of assets enriches investors and partly because the issued public debt requires additional aggregate saving that results in stimulating the business via the multiplier effect. In reality, Japan maintained its economic prosperity until 1997 (the bust of the bubble is estimated to have happened in $1991)^{1}$.

${ }^{1}$ Japanese GDP in 1990 (the year that the bubble culminated) was 450 trillion yen. Before the Asian financial crisis the GDP stood at 510 trillion yen (1997). Although the growth rate remained around $2 \%$, we must note that the Japanese economy had already exploded due to the bubble until 1990. In this sense, it is factitious to regard the Japanese economy during the 1990s as the so-called "the lost decade". Most Japanese enjoyed economic ephemeral prosperity until 1998. 
The above discussion implies that speculative bubbles never emerge without distorting intergenerational resource allocation. As Otaki [3] proves in the overlapping-generations (OLG) model without altruistic individual, the issuance of public debt becomes the future generation's burden in the sense that the issuance lowers the welfare of the descendant when compared with the generation born before the bubble. To summarize, prudential regulations to financial intermediaries and sound fiscal discipline are indispensable measures for hindering speculative bubbles and making an economy sustainable.

The rest of the paper is organized as follows. Section 2 provides an OLG model that contains a bubbly asset. In Section 3, a comparative statics is conducted, exhibiting that a soft-budget government tends to cause speculative bubbles. Section 4 contains brief concluding remarks.

\section{The Model}

\subsection{Individuals}

Based on the models developed by Otaki [4] and [5], a two-period OLG model with a bubbly asset has been constructed. The utility function of individual $i, U_{i}$, is

$$
U_{i} \equiv u\left(c_{i t}, c_{i t+1}\right)-\delta_{i t} \cdot \lambda, c_{i t} \equiv\left[\sum_{j=1}^{m}\left[c_{i t}(j)\right]^{1-\eta^{-1}}\right]^{\frac{1}{1-\eta^{-1}}}, 1<\eta,
$$

where $u$ is a linear homogenous and strictly concave function, which represents the utility obtained by the lifetime consumption. $\lambda$ denotes the disutility of labor. $\delta_{i t}$ is a definition function whose value takes unity when the individual is employed and zero when unemployed. There are a large number of individuals, $n$, to uphold the law of large numbers.

The labor market equilibrium is assumed to be interior in the sense that some individuals are always unemployed in the equilibrium. There are $m$ kinds of goods. For simplicity, marginal labor productivity is assumed to be unity in the overall economy and a commodity is monopolistically produced by the corresponding firm.

Fiat money is the only transaction and value hoarding medium. However, money in this context means the widely defined liquidity, which includes public debt. As the present world economy is facing the historical low interest era, for the purpose of simplicity, we neglect the interest payment for public debt.

In addition to the widely defined liquidity, ahead of all other economic decisions, there is an investment opportunity for risky assets whose expected net return is zero. Let the return of this asset be denoted by $x_{\theta}$. The ex-post rate of return for this asset, $\xi_{\theta}$, is written as:

$$
\xi_{\theta} \equiv \max \left[x_{\theta}, 0\right],
$$

under the limited liability principle. $\theta$ denotes the risk class of this kind of assets. The risk is classified in accordance to the criterion of the second-order stochastic dominance (mean preserving spread). That is, if and only if asset $\theta_{1}$ is riskier than asset $\theta_{2}$, 
then the equation

$$
\int_{-\underline{x}}^{x} F_{\theta_{1}}\left(x_{\theta_{1}}\right) \mathrm{d} x_{\theta_{1}} \geq \int_{-\underline{x}}^{x} F_{\theta_{2}}\left(x_{\theta_{2}}\right) \mathrm{d} x_{\theta_{2}}, \forall x \leq \bar{x},
$$

holds. $F\left(x_{\theta}\right)$ denotes the cumulative distribution function (CDF) of $x_{\theta}$. Equality holds only when $x=\bar{x}$. The interval $[-\underline{x}, \bar{x}]$ is the domain of $x_{\theta}$. It is assumed that there is no mass in CDF and the expected return without the limited liability principle is zero. This leads us to the following equation:

$$
\bar{x}-\int_{-\underline{x}}^{\bar{x}} F\left(x_{\theta}\right) \mathrm{d} x_{\theta}=0, \forall \theta .
$$

In addition, an elementary calculus leads us to

$$
E\left[\xi_{\theta_{1}}\right]>E\left[\xi_{\theta_{1}}\right] \text {. }
$$

This is the property that Stiglitz and Weiss [2] induce.

The lifetime budget constraint after the revelation of the value of $x_{\theta}$ becomes

$$
p_{t} c_{i t}+p_{t+1} c_{i t+1} \leq w_{i t} \delta_{i t}+\pi_{i t}+p_{t} \xi_{i \theta t}-p_{t} \tau_{i t}, p_{t} \equiv\left[\sum_{j=1}^{m}\left[\frac{p_{t}(j)}{m}\right]^{1-\eta}\right]^{\frac{1}{1-\eta}},
$$

where $\pi_{i t}$ refers to the nominal profits, which individual $i$ receives.

The corresponding indirect utility function $I_{i t}$ is

$$
I_{i t} \equiv \frac{w_{i t} \delta_{i t}+\pi_{i t}+p_{t} \xi_{i \theta t}}{\Psi\left(p_{t}, p_{t+1}\right)}-\delta_{i t} \lambda,
$$

where $\Psi$ is a linear homogenous function. Since it is assumed that the equilibrium of the labor market is interior in the sense that some individuals are always unemployed, the equilibrium condition requires that there is no gain by being employed. Accordingly, from Equation (7), the equilibrium nominal wage becomes

$$
w_{t}=\lambda \Psi\left(p_{t}, p_{t+1}\right) .
$$

Meanwhile, since the indirect utility function is a linear function of $\xi_{i \theta t}$, the choice of bubbly asset is separable from other economic decisions; and hence, all individuals invest in the riskiest bubbly asset as far as admissible. This is apparent from inequality (5). If an economy consists of innumerable individuals and the law of large number is upheld, the average private return from such an asset is

$$
\bar{x}-\int_{0}^{\bar{x}} F\left(x_{\bar{\theta}}\right) \mathrm{d} x_{\bar{\theta}},
$$

where $\bar{\theta}$ denotes the admissibly riskier asset. Whenever $\bar{\theta}$ is risky enough, from inequality (5), one must note that the average rate of return of the bubbly asset exceeds that of the alternative investment opportunity: money.

From Equation (4), the following relationship is obtained:

$$
\bar{x}-\int_{0}^{\bar{x}} F\left(x_{\bar{\theta}}\right) \mathrm{d} x_{\bar{\theta}}=\int_{-\underline{x}}^{0} F\left(x_{\bar{\theta}}\right) \mathrm{d} x_{\bar{\theta}} .
$$

The right-hand side of Equation (9) represents the aggregate capital loss of the overall economy. This is a natural consequence that comes from the fact that speculating a 
bubbly asset is essentially equal to participating in a zero-sum game.

What is important in this vein is that a subsidy from the government is necessary to sustain the limited liability principle. As evident in Equation (9), substantial individuals lose money beyond their payment ability. Therefore, once the capital gain of lucky individuals is actualized, this incurs the subsidy to the government for compensating the unpayable capital loss even though time elapses before performing such a rescue for lost investors in reality. Purchasing non-performing debts emerged from the speculative bubble is a typical example. It is assumed that such expenditure is entirely financed by the issuance of new money.

Lastly, as the lifetime utility function is assumed to be linear homogenous, one obtains the following aggregate consumption function, $c$, of young individual:

$$
c \equiv c(\rho) y_{t}, y_{t} \equiv \frac{Y_{t}}{p_{r}}, \rho \equiv \frac{p_{t+1}}{p_{t}}, c^{\prime}>0,0<c(\cdot)<1,
$$

where $Y_{t}$ and $y_{t}$ are nominal real aggregate incomes.

\subsection{Firms}

Firm $j$ faces the following demand function, $D_{j}$ :

$$
D_{j t} \equiv\left[\frac{p_{t}(j)}{p_{t}}\right]^{-\eta} \cdot y_{j t}, y_{j t} \equiv \frac{Y_{t}}{m p_{t}},
$$

where $y_{j t}$ is the real aggregate income per firm. Accordingly, the profit-maximization condition leads us to

$$
p_{t}(j)=\frac{W_{t}}{1-\eta^{-1}} .
$$

Substituting Equation (8) into Equation (12) and aggregating both sides of Equation (12) on $j$, I obtain

$$
p_{t}=\frac{\lambda \Psi\left(p_{t}, p_{t+1}\right)}{1-\eta^{-1}} \Leftrightarrow \Psi(1, \rho)=\frac{1-\eta^{-1}}{\lambda} .
$$

Equation (13) is vital for the theory. The equilibrium inflation rate (or the inverse of the rate of return of the widely defined liquidity) is determined by Equation (13) unrelated to the nominal stock of the widely defined liquidity. This implies that an equilibrium path of the price level can be unaffected by the monetary condition in an economy. Thus, the liquidity becomes non-neutral even though there is no stickiness in prices and the nominal wage. Equation (13) enables us to analyze the macroeconomic implication of speculative bubbles.

\subsection{The Government}

The budget constraint of the government is denoted as

$$
\tau_{t}+\frac{L_{t}-L_{t-1}}{p_{t}}=g_{t},
$$

where $L_{t}$ is the supply of the widely defined liquidity. The left-hand side is the total 
revenue of the government, which consists of the real tax revenue $\tau_{t}$ and the real issuance of the new widely liquidity $\frac{L_{t}-L_{t-1}}{p_{t}}$. The right-hand side is the real government expenditure toward the infrastructure that is indispensable to sustain the economy. It is assumed that government expenditure for each commodity will follow the same pattern as that of the individual.

\subsection{Market Equilibrium}

There are three markets in this model: the goods market, the liquidity market, and the labor market. The two former markets are not independent from the budget constraints of the young generation (6) and the government's budget constraint (14). The aggregate goods market achieves the equilibrium when

$$
\begin{aligned}
& y_{n t}=c(\rho)\left[y_{n t}-\tau_{n t}+E\left(\xi_{\bar{\theta}}\right)\right]+g_{n t}+\frac{l_{n t-1}}{\rho} \\
& \Leftrightarrow y_{n t}=c(\rho)\left[y_{n t}-\tau_{n t}+E\left(\xi_{\bar{\theta}}\right)\right]+\tau_{n t}+l_{n t}, l_{n t} \equiv \frac{L_{n t}}{p_{t}},
\end{aligned}
$$

where subscript $n$ means that the variables are measured by per capita term.

Policy variables are the real tax per capita, $\tau_{n t}$, and the real liquidity per capita, $l_{n t}$. The endogenous variables are, the real income per capita, $y_{n t}$, and the inflation rate, $\rho$. The structural equations are Equations (13) and (15). Thus, the model is completely closed.

\section{Comparative Statics}

\subsection{Monetary-Fiscal Policy and Speculative Bubbles}

This subsection deals with how the tightness of monetary-fiscal policy affects the seriousness of speculative bubbles. It is evident from the discussion in Section 2.1 that the real widely defined liquidity per capita, $l_{n t}$, must exceed the average debt per capita emerging from the bust of the bubble: $E\left(\xi_{\bar{\theta} t}\right) \equiv \int_{-\bar{x}}^{0} F\left(x_{\bar{\theta} t}\right) \mathrm{d} x_{\bar{\theta} t}$. For simplicity, it is assumed that the following relationship is upheld in the provision of the widely defined liquidity:

$$
\begin{aligned}
& l_{n t}-\frac{l_{n t-1}}{\rho}=\bar{l}+E\left(\xi_{\bar{\theta} t}\right), \bar{l}=\text { const., } \\
& l_{n t+i}=l_{n}=\frac{\bar{l}}{1-\frac{1}{\rho}}, \forall i \neq 0
\end{aligned}
$$

Equation (16) implies that the additional widely defined liquidity per capita is entirely included in the compensation for the busted bubble at period $t$ and redeemed within the subsequent period. To put it differently, whenever individuals rationally expect that the monetary authority adopts a more forbearing policy, they speculate a riskier zero-sum asset (they choose an asset that takes a higher value of $\bar{\theta}$ ).

Substituting Equation (16) into Equation (15), one obtains 


$$
y_{n t+i}=c(\rho)\left[y_{n t+i}-\tau_{n t+i}+\chi_{t+i} E\left(\xi_{\bar{\theta}}\right)\right]+\tau_{n t}+\chi_{t+i} E\left(\xi_{\bar{\theta}}\right)+l_{n}, \forall i
$$

$\chi_{t+i}$ takes the value unity if $i=0$, and zero otherwise.

Differentiating both sides of Equation (17), the following result is obtained:

$$
\frac{\mathrm{d} y_{n t}}{\mathrm{~d} \bar{\theta}}=\frac{1}{1-c(\rho)}[1+c(\rho)] \frac{\mathrm{d} E\left(\xi_{\bar{\theta}}\right)}{\mathrm{d} \bar{\theta}} .
$$

Equation (18) implies that there emerge two expansionary effects by more compromising policy of the monetary authority: one is the direct effect that enriches the disposable income by raising the average rate of return for the bubbly asset. This effect appears in the second term in the bracket of Equation (18), the magnitude of which is equal to the value of the multiplier of tax reduction, $\frac{c(\rho)}{1-c(\rho)}$. The other is the indirect effect, which comes from the expansion of the widely defined liquidity provided for the compensation for the busted bubble. The magnitude of this effect is the pure multiplier, $\frac{1}{1-c(\rho)}$, as is evident from the first term in the bracket of Equation (18).

Thus, while the debt incurred by the bust of bubble piles up in conjunction with the compromised and accommodative monetary policy, such a policy possesses an explosive power to upturn the business. This ephemeral temptation urges people to boost the bubble, which results in leaving the burden for the future generation as discussed in the next subsection.

\subsection{Speculative Bubbles as a Burden for the Future Generation}

This subsection considers the intergenerational economic consequence of speculative bubbles. It is assumed that the bubble boosts and busts during period $t$ and the economic welfare is compared with that of the aftermath of the bubble (the welfare of generation $t+1)$. As a reference point, let the welfare of the pre-bubble generation $t-1$ be calculated as well.

For simplicity, it is assumed $\tau_{t-1}=\tau_{t}=0$. From Equation (17), the equilibrium income per capita of generation $t-1, y_{n t-1}$ becomes

$$
y_{n t-1}=\frac{l_{n}}{1-c(\rho)} \text {. }
$$

Similarly, $y_{n t}, y_{n t+1}$ becomes

$$
\begin{aligned}
& y_{n t}=\frac{l_{n}+[1+c(\rho)] E\left(\xi_{\bar{\theta}}\right)}{1-c(\rho)}, \\
& y_{n t+1}-\tau_{n t+1}=\frac{l_{n}}{1-c(\rho)}, \tau_{n t+1}=\frac{E\left(\xi_{\bar{\theta}}\right)}{\rho} .
\end{aligned}
$$

As illustrated in Figure 1, the rational speculative bubble triggered by a compromised monetary policy boosts an economy ephemerally. Before and after the bubble there is no change in the real income per capita as in Equations (19) and (20). A similar result was obtained by Otaki [3]. 


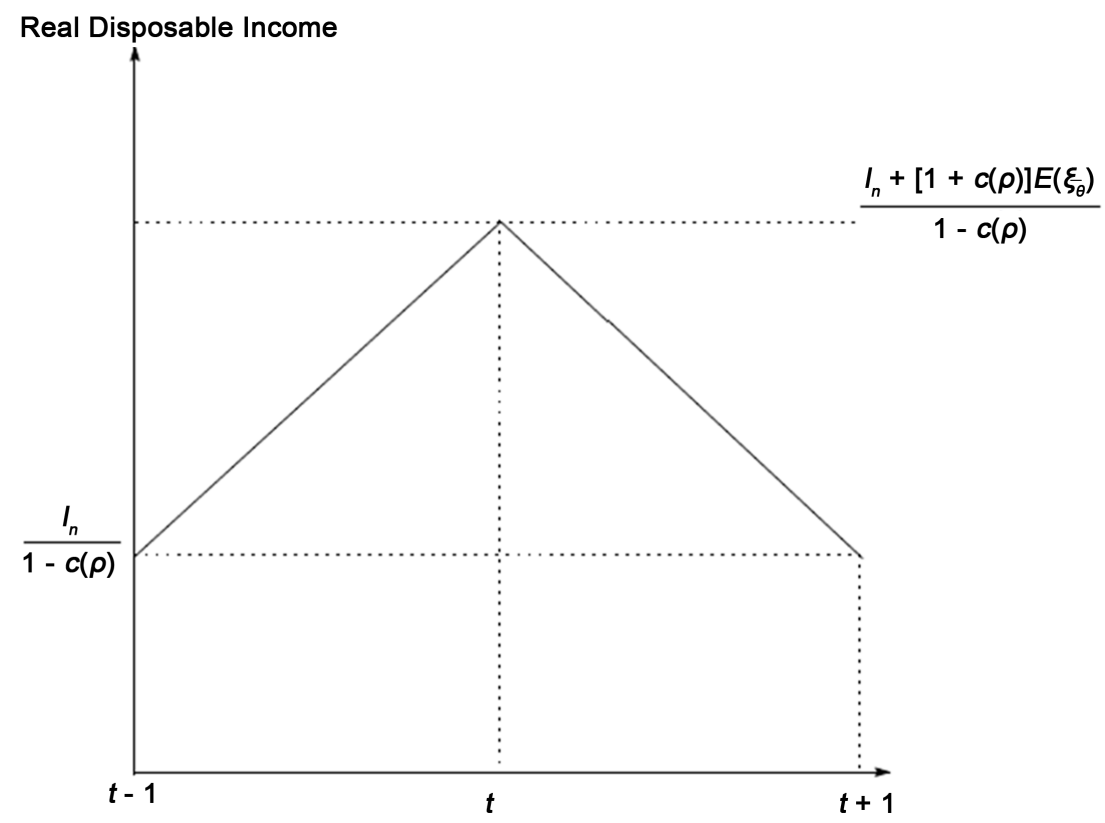

Figure 1. Speculative bubble and real disposable income.

However, this never means that there is no burden for the future generation, which stems from the speculative bubble in the current period. Using the indirect utility function (7), the equilibrium utility of an individual, who belongs to generation $t+i$, is rewritten as

$$
I U_{t+i}=\frac{\eta^{-1} y_{n t+i}-\tau_{n t+i}}{\Psi(1, \rho)},
$$

where $\eta^{-1} y_{n t+i}$ is the income accrued from profits (note that there is no welfare gain from working because the nominal wage stacks at the nominal reservation wage in the imperfect employment equilibrium).

Figure 2 illustrates the lifetime utility level of each generation. Thus, a speculative bubble becomes a burden for the future generation in the sense that individual's wellbeing is lowered compared with those in the pre-bubble generation $t-1$ even though their disposable income is at the same level. Equation (21) can be transformed as

$$
I U_{t+1}=\frac{\eta^{-1} y_{n t+1}-\tau_{n t+1}}{\Psi(1, \rho)}=\frac{\eta^{-1}\left[y_{n t+1}-\tau_{n t+1}\right]-\left[1-\eta^{-1}\right] \tau_{n t+1}}{\Psi(1, \rho)}=\frac{\eta^{-1} y_{n t-1}-\left[1-\eta^{-1}\right] \tau_{n t+1}}{\Psi(1, \rho)} .
$$

The second term in the numerator of Equation (22) reveals the reason why such a burden is generated. As $1-\eta^{-1}$ corresponds to the ratio of income distribution to labor, the second term represents that unfortunate generation $t+1$ is forced to work harder than generation $t-1$ despite the disposable income remaining in the same level. As Otaki [3] showed, Lerner's assertion [6] is incorrect even in a Keynesian framework that allows the possibility of imperfect unemployment equilibrium. Even though the disposable income is unchanged between the pre- and post-bubble generation, the bubble generation (generation $t$ ) incurs on the post-bubble generation the burden of 


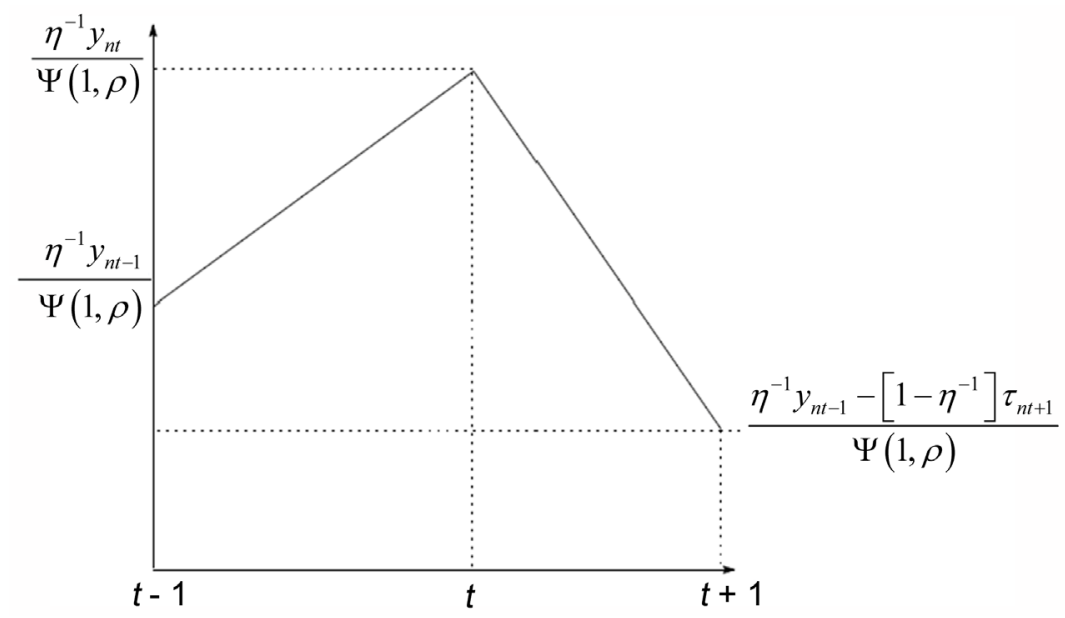

Figure 2. Speculative bubble and economic welfare.

the redemption of the excess widely defined liquidity. Consequently, they are obliged to provide more works without rewards. Meanwhile, such a burden is heavier when the monetary policy is more compromised and the current generation anticipates that they are permitted to invest in riskier assets. This statement is ascertained by Equation (20).

\subsection{Precariousness of Repeated Bubble: Importance of Intergenerational Ethic}

As discussed in the previous subsection, the redemption of the liquidity issued for offsetting the loss of the bubbly asset lowers the welfare of the subsequent generation eventually. Moreover, a speculative bubble brings about ephemeral prosperity to the current generation. Accordingly, the monetary authority dislikes the redemption and prefers to cause a speculative bubble once again. As such, once a compromised monetary policy is settled, speculative bubble is caused successively. This implies that a huge amount of the widely defined liquidity is injected into an economy incessantly.

One must note that there is an upper limit in the volume of circulating liquidity to keep public confidence on its value in terms of goods. Let us assume that the economy reaches the critical point by successive bubbles, in which people start to hold the quantity theoretic rational expectations. Such expectations imply that people disbelieve the intrinsic value of money despite they continue using money $^{2}$. Let the equilibrium price function be denoted as

${ }^{2}$ Let $\kappa_{0}^{-1} \equiv \frac{l_{n 0}}{p_{0}}$ be denoted as the initial position before the quantity theoretic expectation prevails. Since the quantity theory of money is a rational belief, which regards that there is a fixed parity between goods and the liquidity, $\kappa_{0}^{-1}$ might be far larger than $\kappa^{-1}$ when the disbelief in the intrinsic value of money begins to prevail. Accordingly, once such an expectation is generated, the current price level jumps drastically in the following way: individuals anticipate the jump of the price level, and thus they try to purchase goods in exchange of money. However, since all individual take the same action, the rise of the price level or the depreciation of the nominal value of the widely defined liquidity (i.e., the price of public debt) makes $\kappa_{0}^{-1}$ lower to $\kappa_{0}^{-1}$. Succinctly, when the disbelief in the intrinsic value of money is distilled under the excess liquidity situation, hyperinflation and/or plummet of the price of public debt ensues. 


$$
p_{t}=\kappa L_{t}
$$

It is shown that the monetary authority cannot issue the widely defined liquidity any more under Equation (23). The proof is elementary. The following arbitrage is considered. A young individual sells additional unit goods at price $p_{0}\left(=\kappa L_{0}\right)$ in exchange for the liquidity, and repurchases the goods by the obtained liquidity. Since the behavior of individual is identical, all others take the same behavior if profitable. Let us assume that the current liquidity supply increases from $L_{0}$ to $[1+\gamma] L_{0}$. Then, it is evident from Equation (23) that the current price increases by $1+\gamma$. The benefit from such arbitration is

$$
\frac{p_{0}}{p_{1}}-1=\frac{1}{\rho}-1=\left[\frac{1}{1+\gamma}-1\right]<0 \text {, if } \gamma>0 .
$$

Accordingly, no additional issuance is possible once people hold the quantity theoretic rational expectation. This implies that whenever individuals disbelieve the intrinsic value of money owing to the excessive issuance, the government substantively reaches bankruptcy if the tax collection ability is insufficient. This is an appalling consequence of irresponsible sequential speculative bubbles. The discretionary aggregate monetary policy will be ineffective until the confidence on the intrinsic value of money recovers and the quantity theoretic expectation disperses even if it takes a long time.

This discussion suggests the importance of establishing the intergenerational ethic on the monetary-fiscal policy. To avoid the explosive accumulation of the liquidity, the government must pledge to the tight monetary-fiscal discipline that never permit the compensation of the loss of speculative bubbles. If such a discipline is established, every individual correctly realizes the true risk of the bubbly asset, thereby knowing the fact that its private and social return is zero. This is the only way to prevent the emergence of speculative bubbles.

\section{Concluding Remarks}

This study explored the origin of speculative bubbles and analyzed the economic consequences. The obtained results are as follows. First, a feverish bubble, whose rate of return exceeds the rate of interest, originates from the limited liability principle under asymmetric information. In other words, a feverish bubble is a kind of moral hazardous behavior, which is implicitly endorsed by the pecuniary compensation of a government to defeated investors.

Second, a feverish bubble improves the welfare of the concurrent generation. This is partly because a higher rate of return of the bubbly asset increases the aggregate disposable income, and partly because the newly issued liquidity injected for the compensation of defeated investors creates the additional aggregate demand via the multiplier process. However, whenever the additional liquidity is redeemed by the subsequent generation, this becomes a burden for the descendants in the sense that their wellbeing is lowered compared with those in pre-bubble generation. Accordingly, a myopic government is eager to avoid the redemption and prefers to continue the feverish bubble. 
Lastly, when the widely defined liquidity accumulates into a huge amount by the incessant bubbles, individuals start to disbelieve the intrinsic value of money, and as a result, the quantity theoretic rational expectation prevails. When such an expectation is generated, the government is unable to issue additional liquidity. This is because individuals never accept the liquidity, the value of which evidently depreciates under the quantity theoretic rational expectation. This exhausts the revenue resource of the government unless it has sufficient levying ability and endangers the supply of infrastructure, which is the foundation of the economy.

\section{Acknowledgements}

I am grateful for participants of the seminar at Research Institute of Capital Formation at Development Bank of Japan. This study is supported by MEXT/JSPS KAKENHI Grant Number 60183761.

\section{References}

[1] Blanchard, O.J. and Watson, M.W. (1982) Bubbles, Rational Expectations, and Financial Markets. NBER Working Paper, No-w945.

[2] Stiglitz, J.E. and Weiss, A. (1981) Credit Rationing in Markets with Imperfect Information. American Economic Review, 71, 393-410.

[3] Otaki, M. (2015) Public Debt as a Burden on the Future Generation: A Keynesian Approach. Theoretical Economics Letters, 5, 651-658.

[4] Otaki, M. (2007) The Dynamically Extended Keynesian Cross and the Welfare-Improving Fiscal Policy. Economics Letters, 96, 23-29. http://dx.doi.org/10.1016/j.econlet.2006.12.005

[5] Otaki, M. (2015) Keynesian Economics and Price Theory: Re-Orientation of a Theory of Monetary Economy. Springer, Tokyo.

[6] Lerner, A.P. (1944) The Economics of Control: Principles of Welfare Economics. Macmillan, New York.

Scientific Research Publishing

\section{Submit or recommend next manuscript to SCIRP and we will provide best service for you:}

Accepting pre-submission inquiries through Email, Facebook, LinkedIn, Twitter, etc.

A wide selection of journals (inclusive of 9 subjects, more than 200 journals)

Providing 24-hour high-quality service

User-friendly online submission system

Fair and swift peer-review system

Efficient typesetting and proofreading procedure

Display of the result of downloads and visits, as well as the number of cited articles

Maximum dissemination of your research work

Submit your manuscript at: http://papersubmission.scirp.org/

Or contact tel@scirp.org 